See Article page 121.

\section{Commentary: When things just mix like you hoped}

\author{
Matteo Trezzi, MD
}

In this issue of the Journal, Kalangos and colleagues ${ }^{1}$ report a case of pediatric tricuspid valve replacement on a beating heart using the Sapien 3 prosthesis (Edwards Lifesciences, Irvine, Calif). Currently, no tricuspid valve prostheses are available for infants and small children. Therefore, transcatheter valves have been surgically implanted with increasing success in the atrioventricular position with the intention that it allows for subsequent valve expansion in the catheterization laboratory as children grow. Based on its favorable design characteristics and performance in the right ventricular outflow tract position, the Melody valve (Medtronic, Minneapolis, Minn) was initially adapted for left atrioventricular valve replacement with promising results in pediatric patients. ${ }^{2,3}$

More recently, the Sapien 3 valve was proposed as a valid alternative for mitral and tricuspid valve replacement. ${ }^{4,5}$ The stent height is shorter than that of the Melody, and it does not require surgical manipulation beforehand. In small annuli (ie, $<19 \mathrm{~mm}$ ), the Sapien 3 valve certainly appears promising compared with a fixed-diameter prosthesis. However, this valve has thick, stiff leaflets (designed to withstand aortic pressure) that may have poor mobility and may be prone to structural degeneration if complete valve expansion is not achieved. Nevertheless, the choice of the appropriate replacement valve is only one of the steps of a successful challenging surgical operation.

Several features of the article merit mention. The authors are to be congratulated for their meticulous planning and execution of a complex operation. Cardiopulmonary bypass was instituted by directly cannulating the abdominal vessels through a retroperitoneal approach. A small right anterior thoracotomy was used for optimal exposure while avoiding

From the Department of Pediatric Cardiology and Cardiac Surgery, Bambino Gesù Children's Hospital IRCCS, Rome, Italy.

Disclosures: The author reported no conflicts of interest.

The Journal policy requires editors and reviewers to disclose conflicts of interest and to decline handling or reviewing manuscripts for which they may have a conflict of interest. The editors and reviewers of this article have no conflicts of interest.

Received for publication Dec 9, 2020; revisions received Dec 9, 2020; accepted for publication Dec 18, 2020; available ahead of print Dec 25, 2020.

Address for reprints: Matteo Trezzi, MD, Department of Pediatric Cardiology and Cardiac Surgery, Bambino Gesù Children's Hospital IRCCS, Piazza S Onofrio 4, 00165 Rome, Italy (E-mail: trezzim@hotmail.com).

JTCVS Techniques 2021;6:126

2666-2507

Copyright $@ 2020$ The Authors. Published by Elsevier Inc. on behalf of The American Association for Thoracic Surgery. This is an open access article under the CC BY-NCND license (http://creativecommons.org/licenses/by-nc-nd/4.0/).

https://doi.org/10.1016/j.xjtc.2020.12.023

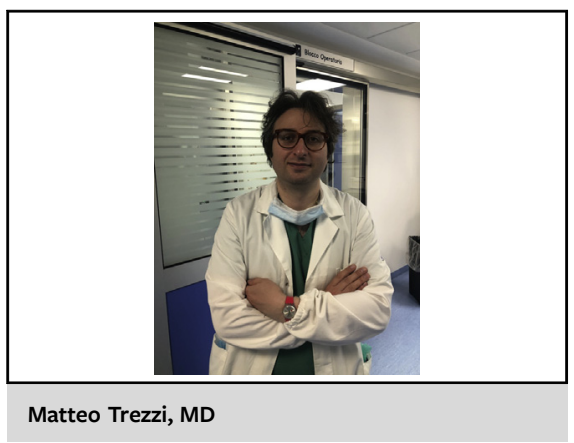

CENTRAL MESSAGE

In reoperative patients, difficult surgical operations may be converted to a less complex surgery combined with an interventional procedure.

resternotomy, and the entire procedure was performed on a beating heart, under transesophageal echocardiographic guidance to avoid any significant compression of the aortic annulus. Ultimately, because the tricuspid annulus was hypoplastic, the newly implanted valve was expanded to the predicted diameter $(23 \mathrm{~mm})$, leaving further room for future percutaneous dilatations (nominal valve size of $26 \mathrm{~mm}$ ).

Additional research is warranted to clarify the long-term durability and optimal postprocedural management of tricuspid transcatheter valve replacement. Antiplatelet therapy or even oral anticoagulation might be considered pending further data, along with strict echocardiographic surveillance of the implanted valve. When percutaneous delivery of the appropriate transcatheter valve is not an option, the surgeon's hope is that interventional techniques in combination with open surgery lead to optimal results.

\section{References}

1. Kalangos A, Shatelen N, Sfyridis P, Dalarizou E, Bonou P. Pediatric tricuspid valve replacement with a transcatheter aortic valve (SAPIEN 3). J Thorac Cardiovasc Surg Tech. 2021;6:121-4.

2. Abdullah I, Ramirez FB, McElhinney DB, Lock JE, del Nido PJ, Emani S. Modification of a stented bovine jugular vein conduit (Melody valve) for surgical mitral valve replacement. Ann Thorac Surg. 2012;94:e97-8.

3. Trezzi M, Cetrano E, Iacobelli R, Carotti A. Edwards Sapien 3 valve for mitral replacement in a child after Melody valve endocarditis. Ann Thorac Surg. 2017; 104:e429-30.

4. Pluchinotta FR, Piekarski BL, Milani V, Kretschmar O, Burch PT, Hakami L, et al. Surgical atrioventricular valve replacement with Melody valve in infants and children. A multicenter study. Circ Cardiovasc Interv. 2018;11:e007145.

5. Fernandez-Doblas J, Perez-Andreu J, Betrain P, Abella R. Pediatric tricuspid valve replacement with transcatheter bioprosthetic valve: an alternative option in highrisk patients. Semin Thorac Surg. 2020;32:1021-3. 